\title{
Influencing Factors on Age-Friendly Interiors
}

\author{
Abraham George* \\ Department of Architecture and Regional Planning, Indian Institute of Technology Kharagpur, India
}

*Corresponding author: Abraham George, Department of Architecture and Regional Planning, Indian Institute of Technology Kharagpur, West Bengal, Pin-721302, India

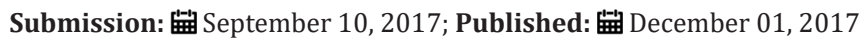

\begin{abstract}
Aging is a progressive accumulation of changes in the living human body with time that are associated with susceptibility to disease, excessive physical strain, lack of physical capability with advancing age. Modernisation and development in science and technology have directly and indirectly affected the aged in living independently. It is for the benefit of all age groups to be together so that each will benefit from others, especially the elder and younger generations. Thus it is imperative to include the preferences of aged in the designing of residential spaces for their productive inclusion in the society. The paper discusses on age-friendly residential spaces which supports the aged to improve their quality of life, self-dependence and wellness.

Age-friendly space facilitates health, well-being and creative participation of people, even as they age; and assures accessible, equitable, inclusive, safe, secure, and supportive built forms. Age-friendly approach looks for equal and healthy participation of aged along with the other age groups. Effective planning for aged involves in-depth understanding of their limitations and problems related to the living space and resolving them in Indian context. Problems faced by elderly are related to vision, mobility, audibility, accessibility and thermal comfort apart from psychological, which are to be considered in design. Selection of materials plays an important role in making the spaces age-friendly. Ergonomic designs following appropriate human anthropometry are central to generate effective designs. Psychological issues are to be dealt separately and improving their self-worth calls for societal interactions and participation in decision making.
\end{abstract}

Keywords: Aging; Age-friendly; Interiors

\section{Introduction}

The world's population is presently undergoing two important demographic shifts; rapid ageing and urbanization. Thus, the number of elderly living in urban area is increasing drastically [1]. In most countries, the fastest growing age group is sixty and older. The number of individuals in this age group is predicted to extend from 841 million in 2013 to more than 2 billion in 2050 [2]. The total population of India is $1,210,854,977$ persons and in that $103,849,040$ persons are elderly with 60 years and above [3], which is $8.57 \%$ of the total population. The increasing trend in the population of India is $1.2 \%$ annually [4], which be reflected in the population of elderly also.

The 2005-2006 National Family Health Survey in India examined there arrangements by household, which is defined by having separate cooking facilities even if older parents and adult children live in adjacent structures. The problems faced by elderly can be categorised into mainly physical problems and mental problems. About $65 \%$ of the aged have to depend on others for their day-to-day maintenance. The situation is worse for elderly females with only $14 \%$ to $17 \%$ being economically independent in rural and urban areas respectively while the remaining is dependent. The elderly males are better off as majority of them .i.e. 51 to $56 \%$ among them in rural and urban, are not dependant on others for their livelihood [5].
In India, both Population Census 2001 and NSSO Survey on Employment Unemployment (2007-08) revealed that nearly $40 \%$ of persons aged 60 years and above; $60 \%$ of men and $19 \%$ of women, are working. In rural areas the proportion is still higher as $66 \%$ of elderly rural men and above $23 \%$ of aged rural women still participate in economic activities, while in urban areas it is only $39 \%$ among elderly men and $7 \%$ of elderly women are economically active after the age of 60 years [5]. It is therefore, essential to consider the preferences and understanding the problems faced by elderly in the designing of interiors and built forms for their effective inclusion in the society.

\section{Problems aged and interiors}

Human body gets adjusted according to the type of life the person's life including type of job or life style which will have an impact on body structure and its parameters. So too are living environments affect humans [6]. Civilised human life style causes adaptation in physical capabilities that may result in problems later. The body somatotypes of the people play an integral role in the designing of residential interiors. Human body consists of $35 \%$ water and $65 \%$ solid in terms of body weight [6].

According to the structure and characteristics of human bodies, they are classified into three type i.e. Endomorph, Mesomorph and 
Ectomorph. While Endomorph is round and flabby and consists of excess body fat, Mesomorph appears to be balanced, bilateral and of firm body structure whereas, Ectomorph appears to be skinny, lean, fragile and weak. Endomorph is mostly found in urban lifestyle and urban aged is found to be prevalent in endomorphism [7]. This will lead later to physical problems related to limbs and joints. Aging process causes sensory losses, visual impairment, and hearing loss, mobility loss with decreased muscle strength and reflex time, as well as lowers energy levels [8].

The percentage of composition of Endomorph: Mesomorph: Ectomorph in Indian population is 3:5:3 in males and 5:3:3 in females [6]. Age-friendly design focuses on making interiors livable and accessible for the aged as well as the other age-groups through increasing their performance ability. Problems are faced in built spaces by elderly are classified under flooring, lighting, acoustics, accessibility, circulation, level changes, ventilation and psychological [8]. The problems are listed under three main types namely Design factors, Physical factors and Psychological factors, for systematic study. Design factors include the problems faced in relation to the design of the interior spaces that includes flooring, barriers, accessibility, lighting, acoustics, ventilation etc. Physical factors include the physical problems which includes problem in vision, audibility, walkablility, weakness etc. Psychological factors are related with the mental health which includes fear of falling, loneliness, feel of security etc.

Interior space has a prominent role in generating quality life of elderly since aging implies progressive loss of abilities which makes them difficult to perform. Most of the interiors are 'not designed elderly friendly' and make them feel hard to cope with [8]. Walking safely inside a house without the fear of falling not only increases their accessibility but also their confidence. The second world assembly on aging [9] held at Madrid, Spain (2003) suggested improving the situation of aged by implementing age-friendliness in built environments which can be understood through the analysis of problems faced by them in varying contexts. Interior space mainly affects the aged in three ways namely; physical, psychological, and performance aspects.

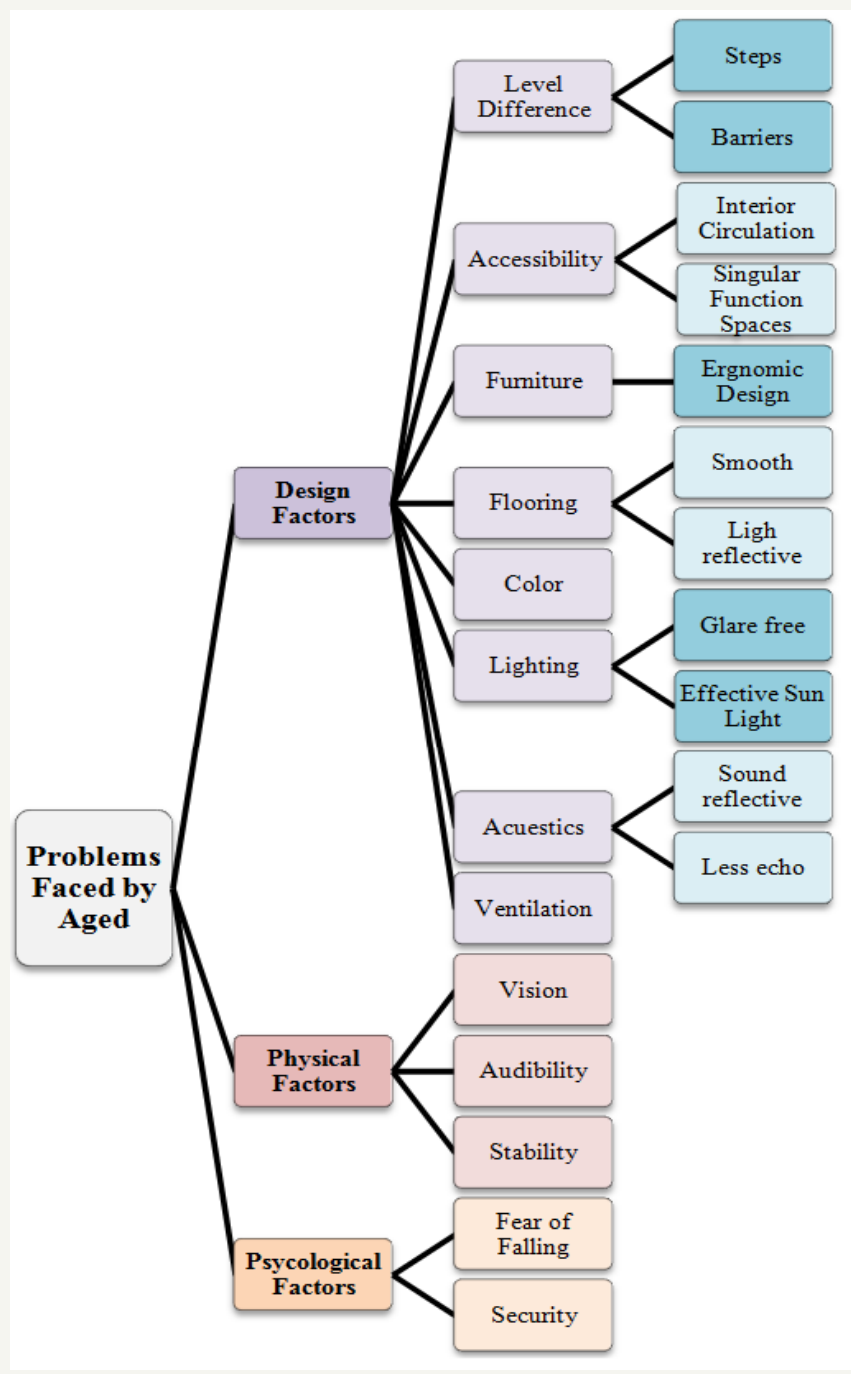

Figure 1: Problems faced by elderly in interior space. 
Major problems faced by elderly in interior space are shown in Figure 1. Problems faced by elderly with respect to design have been further classified into level differences, accessibility and furniture. Physical factors include vision which is related to lighting, audibility which is related to acoustics and stability provided in indoors. Psychological factors here are the problems faced by the elderly that discourages them like fear of falling and safety. Analysis all the listed problems reveal an interesting pattern of interrelationship among them.

\section{Design factors}

Design factors include the problems related to interaction of elderly and the design of the built environment. Built up spaces with many barriers discourage the elderly in terms of mobility which also may result in causing of fatal accidents. Analysis on the factors of design with respect to age-friendliness necessitates a detailed study of accessibility, change in floor levels and texture and form, lighting and acoustics, colour and ventilation in interior designing.

Level difference: Aging leads to physical inabilities and generally aged people have arthritis, osteoporosis or both, decreased muscle strength, lowered manoeuvrability etc. Osteoporosis robs the body of bone density and is the most important risk factor for fractures which is a critical issue; since $94 \%$ of hip fractures occur in people over age 50 and more than $30 \%$ of hip fractures result in death [8]. It is necessary to avoid floor level changes, choose slipresistant type and better quality of flooring, design and detailing of steps; avoidance of barriers of any type. The selection of material and type for flooring is central to make it accident-free for the aged. Use of smooth, reflective and slippery tiles indoors shall be avoided for reducing the chances of slip, glare and fall. Provision of handrails or horizontal grip bars is helpful for elderly (Table 1).

Table 1: Problems with level differences.

\begin{tabular}{|c|c|c|}
\hline Issue & Observation/ Impact & Source \\
\hline $\begin{array}{c}\text { Problems with } \\
\text { stairs }\end{array}$ & $\begin{array}{c}\text { Elderly faces problem in climbing stairs } \\
\text { and prefer lifts. }\end{array}$ & {$[10]$} \\
\hline $\begin{array}{c}\text { Problems with } \\
\text { barriers in } \\
\text { interior design }\end{array}$ & $\begin{array}{c}\text { Elderly and disabled persons face } \\
\text { problems in accessing indoors due to } \\
\text { barriers in routes and access paths. }\end{array}$ & {$[11]$} \\
\hline
\end{tabular}

Entry to a house is the connection to the rest of the world and barrier-free entry makes it easier for aged with wheelchair or ambulant disabled. Avoiding steps throughout the walkway leading from the sidewalk or driveway to the front entrance with comfortable slope of 12 degrees is convenient. Entries leading to the house and to other rooms should not be divided by a projecting threshold, in order to eliminate tripping hazard [12] since falling down' is a common occurrence among elderly and 'fear of fall' causes fear of walking alone, particularly on hard surfaces. Flooring shall be taken care to facilitate independent movement, whether with canes, walkers or wheelchairs, can preserve and support mobility.

Accessibility: Accessibility includes the problems of mobility and circulation of elderly in any built up space. Proxemics, grouping, orientation, and relationship of interior to exterior, easy accesses points etc. play a vital role in making the built form age-friendly. Improving the circulation by making the rooms accessible within closer poxemics provide better accessibility for elderly. Fear of fall, reduces their realms of activity, limits independence and increases social isolation which leads to depression. Multipurpose barrierfree designs will help in improving mobility, safety and quality of life of elderly (Table 2).

Table 2: Problems with accessibility.

\begin{tabular}{|c|c|c|}
\hline Issue & Observation/ Impact & Source \\
\hline $\begin{array}{c}\text { Interior circulation } \\
\text { Problems }\end{array}$ & $\begin{array}{c}\text { Elderly and disabled face problems in } \\
\text { interior circulation inside residential } \\
\text { spaces. }\end{array}$ & {$[11]$} \\
\hline
\end{tabular}

Furniture: Accessing objects in shelves or from the table is seen difficult for the elderly with lowered manoeuvrability. Stretching or reaching for accessories can cause pain in the body parts especially, joint pains for the aged and discourage them from their daily activities. Sitting on an ill-designed chair can hurt their back bone. Sharp edged and hard furniture might cause injury or fall. Thus, care has to be taken in choosing safe, comfortable and accessible furniture for the elderly [8]. Interior furniture plays an important role in generating quality of life in indoor spaces and it is hard to analyse furniture of all types in a single framework but, requires sub-classifying into movable and fixed furniture. Elderly faces problems in sitting and getting up from chairs and stools, to reach out accessories sitting in front of a table, even in using a computer. Most of them prefer to avoid sitting down for $t$ 'fear of getting up' from chairs, especially if it is of low height and light weight. Sitting heights and positions may even cause back pain and stress while implementation of ergonomic design will have a good impact on reducing the physical stress [13].

Ergonomic design is used for a variety of product and facility designs, applications such as chairs and tables, bedroom and dining room furniture, kitchen work tops and storage space, placement of electric switches, door handles, windows, and so forth, which would help elderly people to work and move about easily and conveniently [14]. Heavy but movable furniture can also become barriers for elders in many cases while walking. Chairs misplaced can be the cause for the aged with visual acuity to fall down or even result in fatality. Rectilinear organization with wide paths and clear turning space for wheel chair use facilitates age-friendliness (Table $3)$.

Table 3: Problems with furniture.

\begin{tabular}{|c|c|c|}
\hline Issue & Observation/ Impact & Source \\
\hline $\begin{array}{c}\text { Problems in } \\
\text { furniture system }\end{array}$ & $\begin{array}{c}\text { Elderly face problems due to } \\
\text { ergonomically ill designed furniture, } \\
\text { causing physical damages. }\end{array}$ & {$[6,15]$} \\
\hline
\end{tabular}

Flooring: Flooring is an important part in interior design and its design, materials, detailing and construction has direct impact on the aged as well for all other age groups. Although smooth and polished flooring is preferred by most people, they are slippery and can lead to fatality especially to the elderly. Smooth ground 
floors reflect light inside the house and produce high contrast glare or even temporary blindness [16]. Flooring shall be slip resistant especially in toilets to reduce accidents. It has to be designed with fewer barriers and slope with railings that prevent falling (Table 4). Further, it shall be sufficiently hard, not smooth and resilient which does not facilitate easy movement of wheelchair and weaklimbed elderly. A promising technologic innovation for preventing fall-related injuries is a recently developed safety floor. Under laboratory conditions, this flooring material provides a firm walking surface and, if a fall occurs, reduces the force of impact through energy-absorbing flooring material thus preventing fallrelated hip fractures [17].

Table 4: Problems with flooring.

\begin{tabular}{|c|c|c|}
\hline Issue & Observation/ Impact & Source \\
\hline \multirow{2}{*}{$\begin{array}{c}\text { Problem with } \\
\text { flooring }\end{array}$} & $\begin{array}{c}\text { Slippery surfaces such as wet or polished } \\
\text { floor, or spills of fat or food causing } \\
\text { disturbances. }\end{array}$ & {$[16]$} \\
\cline { 2 - 3 } & $\begin{array}{c}\text { Improper flooring and materials causes } \\
\text { aged to fall down and increase in fear of } \\
\text { falling. }\end{array}$ & [17] \\
\hline
\end{tabular}

Lighting: Studies have found out that from the age of 40, an average person's eyesight gradually worsens and this can lead to an increased risk of fall. By the age of 65 it will be need three times more light to see than a person of age 20 and it causes eyes to take longer to adjust to sudden changes in light and dark and also causes eyes to be more sensitive to glare (Department of Health and Aging, 2004). It is important for safety lighting strategy to improve the living condition of the elderly and to make the most of the eye sight. As a strategy increasing the brightness of lighting and make lighting task-specific may be done. Brightness levels may require adjusting throughout the day, so it's useful to have brightness controls on task and overhead lighting [18] (Table 5).

Table 5: Problems with lighting.

\begin{tabular}{|c|c|c|}
\hline Issue & Observation/ Impact & Source \\
\hline $\begin{array}{c}\text { Improper lighting } \\
\text { causing distress }\end{array}$ & $\begin{array}{c}\text { Improper lighting in interiors causing } \\
\text { distress in aged regarding vision. }\end{array}$ & {$[19]$} \\
\hline
\end{tabular}

Table 6: Problems with acoustics.

\begin{tabular}{|c|c|c|}
\hline Issue & Observation/ Impact & Source \\
\hline $\begin{array}{c}\text { Hearing problem } \\
\text { in interiors due to } \\
\text { design factors }\end{array}$ & $\begin{array}{c}\text { Hearing problem due to improper } \\
\text { interior design causing echo and } \\
\text { high frequency noises. }\end{array}$ & {$[18,20]$} \\
\hline Problem with echo & $\begin{array}{c}\text { Echoing inside the room causes } \\
\text { the hearing problem and } \\
\text { understanding. }\end{array}$ & {$[21,22]$} \\
\hline
\end{tabular}

Acoustics: Sound, in its different manifestations, can have profound impact on elderly ranging from soothing and therapeutic to stressful and disturbing [20] (Table 6). From the study it is understandable that hearing loss is common in elderly. It is necessary to compensate for hearing loss with design measures in order to make the interiors age-friendly. Reducing the unnecessary background noises and avoiding the high-frequency noises can serve up to a level regarding the acoustics of interiors [18].
Colour: One of the most common of the aging effects is loss of vision and increasing risk of vision disorders. Eye is said to be the brain gate and sense of sight is the most important way of communication with around the world [23]. Studies states that using the colours can attract elderly's attention to see the certain target. Colour can play a major role in creating accessible environments. Surface textures and choice of materials provide visual and tactile clues to help people with poor vision. Features of a building which create tonal detail or shadows can also aid the visually impaired [24] (Table 7).

Table 7: Problems with colour.

\begin{tabular}{|c|c|c|}
\hline Issue & Observation/ Impact & Source \\
\hline $\begin{array}{c}\text { Visual haziness } \\
\text { dude to interior } \\
\text { colours }\end{array}$ & $\begin{array}{c}\text { Due to improper usage of colours in } \\
\text { interiors causing visual imperfection } \\
\text { and haziness which also effects in } \\
\text { medical condition of elderly }\end{array}$ & {$[25]$} \\
\hline
\end{tabular}

Ventilation: Ventilation refers to the exchange of indoor air with outdoor air. Without proper ventilation, an insulated house will seal in harmful pollutants, such as carbon monoxide, and moisture that can cause damage. Gases from combustion appliances, like stoves and fireplaces, can accumulate in a poorly ventilated home and threaten health and safety. Excessive moisture can also threaten health, lead to mould growth, ruin insulation, and even cause structural damage. Additionally, elevated levels of humidity can make cooling equipment work harder, leading to higher energy bills [26] (Table 8).

Table 8: Problems with ventilation.

\begin{tabular}{|c|c|c|}
\hline Issue & Observation/ Impact & Source \\
\hline $\begin{array}{c}\text { Problems of } \\
\text { ventilation }\end{array}$ & $\begin{array}{c}\text { Improper ventilation causing health } \\
\text { problems and also impact the liability } \\
\text { for elderly }\end{array}$ & {$[27]$} \\
\hline
\end{tabular}

\section{Physical factors}

Physical factors include the problems faced by elderly due to adverse physical condition and negative impact of built environment. Advancing age brings in bodily system changes that can affect an individual's ability to live independently. Individuals who report difficulty with vision are also more likely to have difficulty with walking, going outdoors and more likely to fall [28]. Physical problems of aged including vision, walkablility/stability and audibility have pertinent importance in the interaction with interior spaces.

Vision: Diminishing eyesight or visual acuity is a common problem found in the elderly. These include reduced ability to discern visual details, reduced contrast sensitivity, impaired ability to adapt to changes light levels, extreme sensitivity to glare, restricted field of vision and depth perception and restricted colour recognition. Although elderly generally need more lighting compared to youth, there are cases like cataract which requires lower light intensity for comfortable vision. Indoor light pollution adversely affects the internal mobility and visual comfort of the aged as well with all other age groups. Aging leads to reduction in 
diameter of pupil of the eye that requires as much as three times light than normal youngsters in order to perceive the shapes and fine details of objects [29].

In general, increasing the level of illumination, eliminating glare, consistent contrast levels and consistent lighting are necessary for age-friendly built environment. Uneven or jarring differences in light levels can cause disorientation and increased levels of agitation and confusion. Adequate lighting combined with appropriate lighting levels can help the elderly to perceive visual details. Gradual changes in light levels, particularly in transition spaces between outside daylight areas and indoor spaces is to be well considered [29]. Sunlight stimulates the circadian and neuro endocrine systems and helps keep the body's systems function in balance, has to be used appropriately in age-friendly indoors [8].

Glare causes tremendous impact on behaviour of elderly since it reduces comfort, produces confusion, agitation and anger in elderly. Glare is formed both directly and indirectly or through reflected light. Direct glare comes from inappropriately shielded light sources and from daylight streaming into a dark room Reflected glare is created by strong light bouncing off a smooth reflective surface. It is necessary to make sure that lighting from the ceiling or through a window is not reflected off by highly polished floors or other surfaces as they cause glare [8]. Carpeting maybe used appropriately in a variety of textures, patterns with nonresilient nature and colours.

Matte finish for paints and wall coverings and soft patterns for furniture and other surfaces are recommended [28]. Light and colour relate to more than just illumination or aesthetic value since they have an influence in sleep, wakefulness, emotions and health. Elderly see colour, patterns and textures much more differently from that by normal youth. With aging the lens of eye hardens, thickens and becomes more yellowish [8]. Aged ones are best able to perceive highly saturated colours at the warm end of the light spectrum, which are shades and hues comprised of reds, oranges and yellows. So too, colours with a high degree of brightness are particularly visible [8]. Age-friendly environment requires good contrasting colours, and hues from adjacent parts of the colour wheel are to be avoided for better visual experience. Use of light colour pattern and texture enhances the design environment and will be of tremendous therapeutic potential for aged ones [8].

Audibility: Audibility is one of the factors that decrease with aging process as high frequency sounds are less audible with aging. So too, lowered sensitivity to lower frequency sounds. Hearing loss not only leads to self-doubt, which affects self-esteem, but also has direct links to physical health [30]. The ability to understand normal conversation is usually not affected in the preliminary stage of aging but when combined with the presence of other background noise; perception is often diminished. Background noise usually gets magnified with the other sounds for the ones using hearing aids. Excessive noise, longer persistence of sound, and echo causes frustration, agitation and anger, elevated blood pressure, heart disease and ulcers in aged [8].
There are also health and safety issues associated with the constant exposure to loud noise for the population in general. Excessive noise, especially intermittent noise at night significantly contributes to sleep disorders [31]. Hearing problems can make it hard to understand and follow the doctor's advice, to respond to warnings, and to hear doorbells and alarms that will lead to potential accidents. It is necessary to select interior surfaces and furnishings so as to have acceptable sonic environment with appropriate amplification of sound level with legibility ensured. Wall surfaces with niches, ceilings with irregularly recessed sections, and appropriately resilient floorings can be used in interiors for diffused sonic environment.

Stability: Aging increases the vulnerability to diseases and other factors that affects the stability of people. Elderly tend to fall due to instability factor which has a direct link with the designing of built space [32]. Elderly generally are unaware of the changes in their abilities which affect their safety while walking, thereby increasing the risk. The stability has a direct link to the psychological state which leads to fear of fall. Stability of aged can be improved by avoiding smooth and sloping surfaces and highly resilient and resistant floorings. Providing grab bars in toilets, with slip resistant flooring reduce the likelihood of fall. Proper measures have to be taken in the design factors considering the walkablility makes the interiors age-friendly.

\section{Psychological}

Aging affects the thinking and psychology and elderly tend to think more for performing even simple tasks. Isolation from the society makes them more into their own world of thoughts which creates the chance for developing irritation and mental fear [33]. Experience reduces age differences in mental abilities, allowing overall effectiveness to be maintained either by preserving the original levels of basic abilities or through the development of compensatory skills. Tasks one has knowledge are less likely to cause mental difficulties than something completely new to the elderly [34]. The detrimental effects on mental functioning associated with increased age are restricted to novel and unfamiliar tasks and are not so much evident on frequently performed activities [32].

Research has shown that elderly have more difficulty in doing things simultaneously than younger people such as driving, reading a document and typing it or reading and listening. There is an increase in the ability to solve problems up to the ages of 40 or 50 years which declines thereafter and the rate of decline is related to their respective. Age-related changes in mental ability appear early in adult life and there is increasing evidence that an individual's age vs ability change markedly, especially beyond the age of 50 [25]. Mental abilities appear to deteriorate at different rates, depending on whether they are based on bodies of information 'acquired over long periods of time' or through 'rapid assimilation and analysis'. An implication of this view is that, while age differences might not be evident in typical activities, they may become apparent if some type new and of unusual stress or complication is present, as is often the case when learning new skills or the use of new equipments. 


\section{Fear of fall}

Age-related changes in physical ability are one of the reasons for the fear of falling. This fear adds on with barriers, slops, slippery surfaces etc., in interiors discourage elderly to perform their daily tasks. Confusion of performing multi tasks can also cause fear of fall in them. Design factors and Physical factors have the direct link in the developing of such a psychological fear. Creating fear less interiors can positively impact the lives of elderly and improve their quality of life.

\section{Security}

The loss of energy and reduced resistance skills make elderly worried about their own security from external intruders. Developing of such a fear pushes them more into isolation and depression. Advanced and easy locking system, burglar alarm, awareness of proximity to police station, better connectivity with the community they live in, and enabling technologies play vital role in making them feel secure. So too, proximity to hospitals or clinics and medical stores, and the availability of ambulance give better security feeling to elders.

\section{Conclusion}

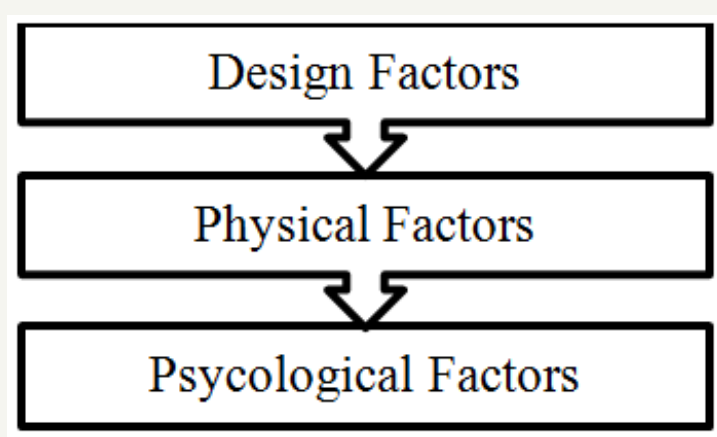

Figure 2: Influence diagram of main problems.

Age friendly interiors are mainly influenced by the Physical factors, design factors and psychological factors. The analysis of almost all problems of the elderly establishes the interrelatedness, and solving one can result in relative solving of other problems too. However, there are contradicting situations too arising as in the case of visual acuity and cataract cases. The study establishes that the Psychological factors are closely related to both design factors and physical factors and each of the variable listed above has a profound impact on the quality of life of the elderly. The study opens the way for a potential for developing an 'index based on problematic variables' and a 'rating system' for age-friendly interiors. From the study it can be inferred that design factor influences both the physical and psychological factors but physical factor can only influence psychological factor as shown in Figure 2. Thus improving the design factors and physical factors will improve psychological factors and contribute to improved age friendliness.

Age-friendly design focuses on developing the facilities friendly to all age groups especially elderly. According to the present demographic trends population of elderly is increasing compared to the early decades which demands designing human habitats, age friendly. The paper clearly outlines the major problems faced by the aged in their living habitats in terms of lighting, acoustics, flooring and accessibility and finding appropriate solution will lead to developing a guideline for age-friendly designs. It may be seen that age-friendly designs has positive impact on all the age groups also and shall be the 'norm for all future developments' both in rural and urban areas.

\section{References}

1. WHO (2014) Measuring the age-friendliness of cities: A Guide to using core indicators. World health organization centre for health development, Kobe, Japan.

2. UNDESA (2011) United Nations department of economic and social affairs. World urbanization prospects: The 2011 Revision. New York, USA.

3. (2011) C-13 Single year age returns by residence and sex. Census of India.

4. World Bank (2016) Public data tool.

5. (2011) Situation analysis of the elderly in India, Central statistics office, Ministry of statistics \& programme implementation, Government of India, India.

6. Chakrabarti D (1997) Indian anthropometric dimentions (for ergonomic design practice). National institute on design.

7. Pradeepa R, Anjana RM, Joshi SR, Bhansali A, Deepa M, et al. (2015) Prevalence of generalized \& abdominal obesity in urban \& rural Indiathe ICMR-INDIAB study (phase-i) [ICMR-INDIAB-3]. Indian J Med Res 142: $139-150$.

8. Brawley B, Taylor M (2003) Designing for senior care environments. Architech Magazine.

9. Second world assembly on aging (2002) Political decleration and madrid international plan of action on aging. Madrid, Spain.

10. Edwards, Lockett (2005) Steps to safer stairs-A kit for improving stair safety. Community health research unit, University of Ottawa, Canada.

11. (1998) Guidlines and space standerds for barrier free built environment for dissabled and elderly persons. CPWD, Ministry of urban affaires and employment, India.

12. (2015) National age in place council (NAPC), Making your home senior friendly. Age in place.

13. Molenbroek JFM (1987) Anthropometry of elderly people in the Netherlands: Research and applications 18(3): 187-199.

14. Kamal K, Samuel T (2001) Anthropometry for design for the elderly. International Journal of Occupational Safety and Ergonomics 7(1): 1534.

15. Fozard JL, Graafmans JAM, Rietsema J, Bouma H, Berlo AV (1996) Aging and ergonomics: the challenges of individual differences and environmental change. Center for biomedical and health care technology, Netherlands.

16. (2004) Don't fall for it. Falls can be prevented! A guide to preventing falls for older people. State government of South Australia.

17. Al-Faisal W (2006) Falls prevention for older persons.

18. Mitchell T, Longyear S (2006) Ergonomics \& Aging.

19. Figueiro, Mariana G (2001) Lighting the way: a key to independence. Lighting research center, Rensselaer polytechnic institute, New York, USA.

20. Joseph A, Ulrich R (2007) Sound control for improved outcomes in healthcare settings. The center for health design, USA. 
21. Wenger (2000) Acoustic problems \& solutions for rehearsal and practice spaces.

22. (2010) Acoustics in healthcare environments. CISCA, India.

23. Haghnia S, Mostaghni A, Foroughan M (2016) Securing of elderly houses in term of Elderly's vision disorders 159-168.

24. Dalke H, Littlefair PJ, David LL, Camgöz N (2004) Lighting and colour for hospital design-R\&D Report $\mathrm{B}(01) 02$, London south bank university, Wales, UK.

25. Kortney JE (2003) Wall color of patient's room: effects on recovery. The university of florida, Florida, USA.

26. (2010) Guide to home ventilation. US Department of energy, EERE Information Center.

27. WHO 2015. Age-friendly environments. Ageing and life-course.

28. Campbell VA, Crews JE, Moriarty DG, Zack MM, Blackman DK (1999) Surveillance for sensory impairment, activity limitation, and health- related quality of life among older adults-united states, 1993-1997. MMWR CDC Surveill Summ 48(8): 131-156.

29. Barrison G (2015) What goes into designing an age-friendly home? Stylised interiors.

30. Hsieh DL, Lin KN, Ho JH, Liu TH (2009) Hearing in noise test in subjects with conductive hearing loss. J Formos Med Assoc 108(12): 937-942.

31. Askill MS (2016) Designing for acoustics, hearing and aging. ASID.

32. Kent S, Fildes B (1997) A review of walk-with-care: an education and advocacy program for older pedestrians. Monash University Accident Research Centre, Australia.

33. Haigh R (1993) The ageing process: a challenge for design. Appl Ergon 24(1): 9-14.

34. Hosseinpoor AR, Bergen N, Chatterji S (2013) Socio-demographic determinants of caregiving in older adults of low-and middle-income countries. Age Ageing 42(3): 330-338. 